\title{
Prevalence and determinants of condom utilization among people living with HIV/AIDS in Egypt
}

I. Wahdan, ${ }^{1}$ A. Wahdan, ${ }^{2}$ M. El Gueneidy ${ }^{3}$ and I. Abd El Rahman ${ }^{4}$

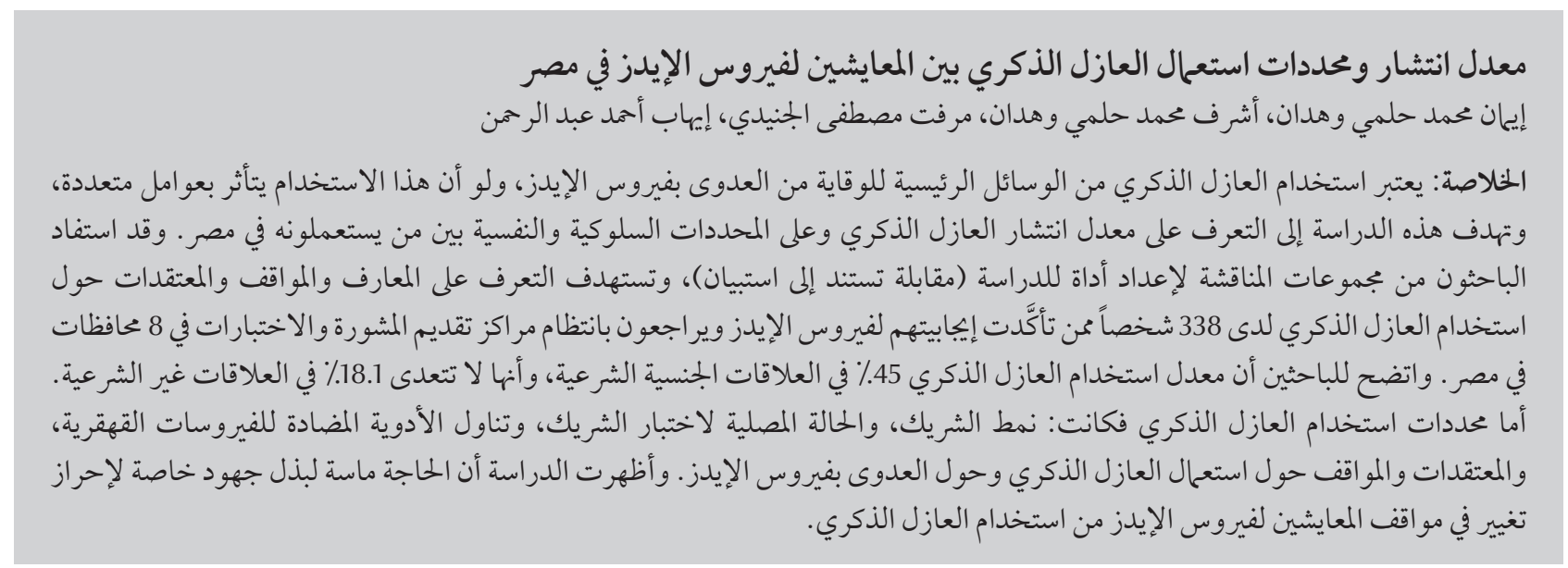

ABSTRACT Condoms are an integral part of HIV/AIDS prevention, yet their use is affected by several factors. The purpose of this study was to determine the prevalence of condom use and the psychological and behavioural determinants among people living with HIV/AIDS in Egypt. Focus group discussions were used to develop the study tool (questionnaire interview) geared towards eliciting knowledge, attitudes and beliefs about condoms among 338 confirmed HIV-positive persons attending fixed voluntary counselling and testing centres in 8 governorates in Egypt. The prevalence of condom use was 45.0\% in regular sexual relations and only $18.1 \%$ in casual relations. The determinants of condom use were: type of partner, serostatus of partner, antiretroviral intake, beliefs and attitudes towards condom use and to HIV infection. The study shows that special efforts need to be made to change the attitudes of people living with HIV/AIDS towards condom use.

\section{Prévalence et déterminants de l'utilisation du préservatif chez les personnes vivant avec le VIH/sida en Égypte}

RÉSUMÉ Si les préservatifs font partie intégrante de la prévention du VIH/sida, leur utilisation dépend toutefois de plusieurs facteurs. L'objectif de la présente étude était de déterminer la prévalence de l'utilisation du préservatif et les déterminants psychologiques et comportementaux de son utilisation chez des personnes vivant avec le VIH/sida en Égypte. Des discussions de groupes ciblées ont été organisées pour mettre au point l'instrument utilisé pour l'étude (entretien par questionnaire) visant à mettre en évidence les connaissances, les attitudes et les croyances relatives aux préservatifs chez 338 personnes au statut VIH confirmé qui consultent dans des centres de dépistage et de conseil volontaires fixes dans huit gouvernorats en Égypte. La prévalence de I'utilisation du préservatif était de 45,0 \% dans les relations sexuelles avec un partenaire régulier mais seulement de $18,1 \%$ dans les relations avec des partenaires occasionnels. Les déterminants de l'utilisation du préservatif étaient les suivants : le type de partenaire, le statut sérologique du partenaire, la prise d'antirétroviraux, les croyances et les attitudes concernant l'utilisation du préservatif et l'infection à VIH. L'étude démontre que

${ }^{7}$ Department of Epidemiology; ${ }^{2}$ Department of Biostatistics, High Institute of Public Health; ${ }^{3}$ Department of Psychiatry and Mental Health Nursing, Faculty of Nursing, University of Alexandria, Alexandria, Egypt (Correspondence to I. Wahdan: imanwahdan@yahoo.com).

${ }^{4}$ National AIDS Programme Manager, Ministry of Health and Population, Cairo, Egypt.

Received: 23/09/12; accepted: 18/11/12 


\section{Introduction}

Human immunodeficiency virus (HIV) transmission in several parts of the world is mainly through sexual contact. This is particularly true in sub-Saharan and North Africa [1,2]. It has been shown that condoms are an integral part of prevention of transmission of sexually transmitted infections (STIs) and HIV/AIDS, and correct use of them reduces the risk of HIV transmission by almost $100 \%[1,2]$. Making condoms more accessible, lowering their cost, promoting their use extensively and helping to overcome social and personal obstacles that limit their use are some of the widely advocated strategies in the fight against the AIDS pandemic [3,4]. Nevertheless, condoms can have little impact in preventing HIV if people do not use them. There are contrasting reports on condom use among people living with HIV (PLHA) and among those using antiretroviral treatment $[5,6]$. The success of highly active antiretroviral therapy (HAART) in reducing the morbidity and mortality from HIV/ AIDS has been widely documented $[5,7]$. Consequently many HIV-infected persons are now living longer, healthier and more productive lives. Yet such treatment may have unintended effects on sexual behaviour. Some studies suggest that since HAART became available, the prevalence of unprotected sex and the incidence of STIs including HIV have increased $[6,8]$. Initiation of HAART has been reported to be associated with increased sexual risk behaviour and decreased condom use [9]. Some other studies have reported lower high-risk sexual behaviour among HAART patients [10-12].

In spite of its importance, condom use is among the most difficult issues to address in designing prevention programmes. This is due to different social, cultural and personal factors [13]. In Egypt, Kabbash et al. in 2007 found that obstacles to condom use included perceived lack of need, rejection by partners and hazards of condoms [14]. Identifying the determinants of condom use is important in developing effective HIV preventive interventions [2]. The literature indicates that beside HAART initiation, factors affecting condom use include a range of situational, interpersonal and structural factors such as knowledge about AIDS, behavioural intention, perceived susceptibility, perceived barriers, self-efficacy and demographic factors $[15,16]$.

By far the most frequent mode of transmission of HIV in Egypt is through sexual contact. It is estimated that $76 \%$ of all those infected with HIV in Egypt contracted it through sexual intercourse with an infected person. Moreover, a substantial number of Egyptian HIVinfected women have contracted the infection from their HIV-positive spouses [17]. This raises the importance of studying condom use and the different psychosocial and behavioural determinants of condom use among HIV infected persons in Egypt. This study aimed to identify the determinants of condom use among a group of PLHA with the hope of identifying and addressing constraints on condom use in Egypt.

\section{Methods}

A cross-sectional design was used for the study, which was carried out in May and June 2012.

\section{Study setting and sample}

The study sample was selected from confirmed PLHA attending the fixed voluntary counselling and testing centres (VCT) in 8 governorates in Egypt (Cairo, Alexandria, Dakahlia, Sharqia, Qalioubia, Fayoum, Menya and Assiut). The total number of PLHA registered in these centres amounted to nearly 2400 , with a male to female ratio of nearly 4:1. Using Epi Info and based on an estimated prevalence of $70 \%$ of condom use among HIV-positive persons and a precision of 5\% around the expected prevalence and using a 5\% level of significance and an alpha error of $5 \%$, the minimum required sample size amounted to 250 PLHA, with a minimum of 200 males and 50 females.

A random systematic sample of 374 PLHA wastaken from all those recorded at the selected centres. The participants were randomly selected from a list of PLHA recorded at the selected centres. In order to respect confidentiality they were approached by their counsellors. During data collection 36 people did not want to continue the interview so the study was carried out on 338 PLHA.

\section{Questionnaire development}

The study tool (questionnaire interview) was developed based on the results of a preliminary qualitative study in the form of focus group discussions (FGD) conducted with a sample of HIV-positive persons (20 males and 14 females) attending VCT who agreed to attend a private meeting to discuss condom use. Discussions took place in 4 focus groups ( 2 for males and 2 for females) and participants were selected for each group based on similar age and educational background but from different centres to avoid knowing each other. Each group was led by one of the researchers using a discussion guide comprising open-ended questions to encourage a range of responses related to factors affecting utilization and nonutilization of condoms.

The ideas that emanated from the FGD in addition to literature reviews were analysed and used to develop a semi-structured questionnaire composed of 79 closed-and open-ended questions. It took 15-20 minutes to complete. It was geared towards eliciting information related to condom use and its determinants. It also included questions on knowledge about the condom and how to use it and on intentions, attitudes and beliefs towards condom use. It also included determinants 
such as accessibility and availability of condoms and reasons for their use.

\section{Data collection}

The interviews were conducted in HIV/ AIDS counselling centres by trained HIV/AIDS counsellors. An informed consent was taken from each participant before interviews were conducted. The purpose of the research, confidentiality of information, benefit of participation was explained to the participants. Anonymity and confidentiality were guaranteed and maintained. Ethical concepts of respect for truth and respect of people were considered.

\section{Analysis}

Descriptive statistics (numbers and percentages) were used for reporting and summarizing qualitative data. Minimum, maximum, arithmetic mean and standard deviation (SD) were used as measures of central tendency and dispersion respectively for normally distributed quantitative data. The chisquared test was used to test the association between 2 qualitative variables or to detect difference between 2 or more proportions. The data were analysed using SPSS software, version 16.0. $P<$ 0.05 level was used as the cut-off value for statistical significance.

\section{Results}

\section{Sociodemographic characteristics of respondents}

Table 1 shows the sociodemographic characteristics of the studied PLHA ( 253 males and 85 females). As regards the age distribution, the highest percentage $(24.0 \%)$ were in the age group $30-<35$ years, followed $35-<40$ years $(19.5 \%)$ and $45+$ years (18.3\%). The mean age was 36.7 years. As regards marital status, $21.0 \%$ were single, $53.0 \%$ married and the rest (26.0\%) divorced, separated or widowed. The level of education of the studied PLHA showed a mixed group with $18.0 \%$ illiterate and

\begin{tabular}{|c|c|c|}
\hline Sociodemographic characteristic & No. & $\%$ \\
\hline \multicolumn{3}{|l|}{ Sex } \\
\hline Male & 253 & 74.9 \\
\hline Female & 85 & 25.1 \\
\hline \multicolumn{3}{|l|}{ Age (years) } \\
\hline$<25$ & 26 & 7.7 \\
\hline $25-$ & 47 & 13.9 \\
\hline $30-$ & 81 & 24.0 \\
\hline $35-$ & 66 & 19.5 \\
\hline $40-$ & 56 & 16.6 \\
\hline $45+$ & 62 & 18.3 \\
\hline \multicolumn{3}{|l|}{ Marital status } \\
\hline Married & 179 & 53.0 \\
\hline Single & 71 & 21.0 \\
\hline Divorced/separated or widowed & 88 & 26.0 \\
\hline \multicolumn{3}{|l|}{ Educational level } \\
\hline Illiterate & 61 & 18.0 \\
\hline Primary & 47 & 13.9 \\
\hline Preparatory & 31 & 9.2 \\
\hline Secondary & 107 & 31.7 \\
\hline University and higher & 92 & 27.2 \\
\hline \multicolumn{3}{|l|}{ Employment } \\
\hline Regularly employed & 86 & 25.5 \\
\hline Irregular work & 66 & 19.5 \\
\hline Private work & 42 & 12.4 \\
\hline Do not work & 144 & 42.6 \\
\hline \multicolumn{3}{|l|}{ Place of residence } \\
\hline Rural & 93 & 27.5 \\
\hline Urban & 186 & 55.0 \\
\hline Squatter & 59 & 17.5 \\
\hline \multicolumn{3}{|l|}{ High-risk group } \\
\hline None & 188 & 55.6 \\
\hline Men having sex with men & 70 & 20.7 \\
\hline Commercial sex worker & 20 & 5.9 \\
\hline IV drug user & 42 & 12.4 \\
\hline More than 1 risk group & 18 & 5.3 \\
\hline
\end{tabular}

$I V=$ intravenous.

$27.2 \%$ with university and postgraduate levels. The highest proportion of the studied PLHA had finished secondary education (31.7\%). In terms of occupation, $42.6 \%$ of the respondents did not work and $19.5 \%$ did irregular work; only $25.4 \%$ had regular work and $12.4 \%$ were engaged in private sector work. More than half $(55.0 \%)$ of the studied sample lived in urban areas, $27.5 \%$ in rural areas and $17.5 \%$ in squatter areas.

When asked if they belonged to any of the most at-risk population groups, more than half of them (55.6\%) denied being in any highrisk group. The remainder indicated that they were men who had sex with men (20.7\%), commercial sex 
workers (5.9\%) or intravenous drug users (12.4\%), while $5.3 \%$ belonged to more than 1 group.

\section{Knowledge about condoms and training in their use}

Apart from the 8 respondents who claimed they had not heard about condoms before, all the study population knew about and had seen condoms (Table 2). As many as $80.8 \%$ reported receiving formal training on condom use. The main sources of information and also training were the VCTs and the Egyptian National Programme for Prevention and Control of AIDS from which almost two-thirds of the PLHA had received information and been trained on condom use. Support groups, followed by friends, came next in importance, while the media including the Internet played a minor role in information (6.4\%) and a minimal role in training on condom use.

\section{Availability of condoms}

All the study respondents except 21 (6.2\%) agreed that condoms were available. The Egyptian national programme for prevention and control of AIDS and the VCTs were the main sources (42.0\% and $16.7 \%$ respectively) (Table 3). Pharmacies appeared also to be a main source (37.5\%). Other sources included civil societies and friends, who played a minor role as a source of condoms. Asking those who were using condoms distributed by the national AIDS programme $(n=239)$ about their satisfaction with the condoms, more than half (53.0\%) mentioned that they were good. Another $27.0 \%$ stated that they were not different than other condoms. Only 20.0\% were not satisfied with them, mainly because of the logo on them. Other reasons were general to condoms such as decreasing pleasure and the size.

\section{Condom use during the last 6 months}

Table 4 shows respondents' use of condoms during the last 6 months when having sexual relations with regular partners and in casual sexual relations. The table shows that 242 persons had sexual relations with a regular partner and 149 had casual sexual relations during the last 6 months. It is clear that condoms were more frequently used in sexual relations with regular partners than in casual sexual relations. Those who reported using them 100\% of the time were $45.0 \%$ in regular sexual partnerships but only $18.1 \%$ in casual sexual relations. The reverse was seen as regards non-use of condoms which amounted to $59.1 \%$ in casual partnership while it was only $25.6 \%$ in regular partnership. The difference was statistically significant $\left(\chi_{4}^{2}=48.13\right.$, $P<0.001)$.

\section{Intention of condom use during the next 6 months}

Table 5 shows that $74.0 \%$ of the study population intended to use condoms during sexual relations with regular partners, which was similar to the proportion who actually used condoms during the last 6 months. As regards the intention to use condoms during casual sexual relations, $55.0 \%$ of the study population indicated this intention, which was slightly higher than reported use during the last 6 months. The proportion intending to use condoms in regular sexual relationships was significant higher than in casual relations $\left(\chi_{3}^{2}=30.8, P<0.001\right)$.

When asked whether their intentions to use condoms would be influenced by knowledge about the serological status of the sexual partner in a casual relationship, Table 6 shows that $52.7 \%$ would decide to use a condom if the partner's serostatus was unknown, $48.2 \%$ if the partner was known to be seronegative and only $39.6 \%$ if the partner was known to be seropositive $\left(\chi_{4}^{2}=12.89, P=0.012\right)$.

\section{Beliefs about the impact of regular condom use in casual sexual relationships}

All the respondents were asked a set of specific questions on their beliefs about the positive and negative impacts of regular condom use in casual relationships. Table 7 shows that the majority of the study sample believed that condom

\begin{tabular}{|c|c|c|c|c|}
\hline \multirow[t]{2}{*}{ Variable } & \multicolumn{2}{|c|}{ Heard about condoms } & \multicolumn{2}{|c|}{ Trained on condom use } \\
\hline & No. & $\%$ & No. & $\%$ \\
\hline Heard and trained about condoms & \multicolumn{2}{|c|}{$(n=338)$} & \multicolumn{2}{|c|}{$(n=338)$} \\
\hline Yes & 330 & 97.6 & 273 & 80.8 \\
\hline No & 8 & 2.4 & 65 & 19.2 \\
\hline Source of information & \multicolumn{2}{|c|}{$(n=330)$} & \multicolumn{2}{|c|}{$(n=273)$} \\
\hline Counselling and voluntary testing centre & 121 & 36.7 & 107 & 31.7 \\
\hline National AIDS programme & 107 & 32.4 & 101 & 27.0 \\
\hline Support group & 60 & 18.2 & 60 & 22.0 \\
\hline Friends/sex partners & 65 & 19.7 & 36 & 13.2 \\
\hline Media and internet & 21 & 6.4 & 3 & 1.1 \\
\hline Other & 7 & 2.1 & 2 & 0.7 \\
\hline
\end{tabular}




\begin{tabular}{lcc}
\hline $\begin{array}{l}\text { Table } 3 \text { Distribution of the study group living with HIV/AIDS by sources of } \\
\text { obtaining condoms, Egypt } 2011(\boldsymbol{n}=\mathbf{3 1 7})\end{array}$ & No. \\
\hline Source of condoms & 133 & 42.0 \\
National AIDS programme & 53 & 16.7 \\
Counselling and voluntary testing centre & 119 & 37.5 \\
Pharmacies & 13 & 4.1 \\
Civil societies & 10 & 3.2 \\
Friends/support groups & 2 & 0.6 \\
\hline
\end{tabular}

Multiple answers were allowed.

use would prevent transmission of the infection to their partner (83.4\%), would protect them from acquiring STIs (82.2\%) and from acquiring another HIV (79.0\%) and would prevent guilt feelings afterwards $(66.0 \%)$ and $55.9 \%$ that it allowed them to continue having sexual relations.

Answers of the study group to their beliefs about commonly mentioned negative aspects of condom use during every casual sexual relationship showed that $55.9 \%$ believed they decreased pleasure, prevented spontaneity $(43.2 \%)$, interfered with the flow of sexual relationships (46.2\%), made a barrier to intimacy and love (38.2\%), resulted in loss of confidence with the partner (33.4\%) and resulted in erection problems (26.0\%). A proportion, ranging between one-quarter and onethird, of the study group did not have specific beliefs about the commonly mentioned negative aspects in condom use in every casual sexual relationship.

\section{Reasons for use or non-use of condoms}

Respondents were asked why an HIV infected person used or did not use condoms in sexual relations. Table 8 shows that the main reason stated for condom use was protection from infection (93.7\%). Other reasons mentioned included fear from God, guilt feelings and psychological reasons. Reasons given for non-use of condoms included personal reasons and reasons related to the condom itself. The most common were classified as revenge ("Why was I infected? I should infect others the same way I was infected") and lack of conscience (55.0\%) followed by the desire to get full pleasure (44.4\%). Other reasons included ignorance (32.9\%), psychological factors (20.5\%) and partner refusal (7.3\%). Unavailability of condoms was mentioned as a reason by another $7.3 \%$ of respondents.

\section{Discussion}

Condoms are the only means of prevention of HIV by sexual transmission for persons who practise sex. For PLHA who wish to continue their sexual behaviour, condom use can protect

\begin{tabular}{|c|c|c|c|c|}
\hline \multirow[t]{2}{*}{ Frequency of use } & \multicolumn{2}{|c|}{$\begin{array}{l}\text { Regular partner } \\
\qquad(n=242)\end{array}$} & \multicolumn{2}{|c|}{$\begin{array}{l}\text { Casual partner } \\
\qquad(n=149)\end{array}$} \\
\hline & No. & $\%$ & No. & $\%$ \\
\hline Never & 62 & 25.6 & 88 & 59.1 \\
\hline Rarely & 27 & 11.2 & 15 & 10.1 \\
\hline Half the time & 32 & 13.2 & 15 & 10.1 \\
\hline Most of the time & 12 & 5.0 & 4 & 2.7 \\
\hline Always & 109 & 45.0 & 27 & 18.1 \\
\hline
\end{tabular}

$\chi_{4}^{2}=48.13, P=0.001$.

Rarely $=25 \%$ of the time; most of the time $=75 \%$ of the time.

\begin{tabular}{|c|c|c|c|c|}
\hline \multirow[t]{2}{*}{ Intention to use } & \multicolumn{2}{|c|}{ Regular partner } & \multicolumn{2}{|c|}{ Casual partner } \\
\hline & No. & $\%$ & No. & $\%$ \\
\hline Yes & 250 & 74.0 & 186 & 55.0 \\
\hline No & 62 & 18.3 & 91 & 26.9 \\
\hline Not decided & 21 & 6.2 & 56 & 16.6 \\
\hline Do not intend to have sex & 5 & 1.5 & 5 & 1.5 \\
\hline
\end{tabular}

$\chi_{4}^{2}=12.89, P=0.012$. 


\begin{tabular}{|c|c|c|c|c|c|c|}
\hline \multicolumn{7}{|c|}{$\begin{array}{l}\text { Table } 6 \text { Distribution of the study group living with HIV/AIDS about the influence of their knowledge about the serologica } \\
\text { status of the partner on condom use in a casual relationship, Egypt } 2011(n=338)\end{array}$} \\
\hline \multirow[t]{3}{*}{ Influence on decision to use condom } & \multicolumn{6}{|c|}{ Serological status of casual partner } \\
\hline & \multicolumn{2}{|c|}{ Positive } & \multicolumn{2}{|c|}{ Negative } & \multicolumn{2}{|c|}{ Unknown } \\
\hline & No. & $\%$ & No. & $\%$ & No. & $\%$ \\
\hline Yes & 134 & 39.6 & 163 & 48.2 & 178 & 52.7 \\
\hline No & 178 & 52.7 & 152 & 45.0 & 134 & 39.6 \\
\hline Don't know & 26 & 7.7 & 23 & 6.8 & 26 & 7.7 \\
\hline
\end{tabular}

them from reinfection with HIV or STIs and prevent them from infecting their partners $[1,2]$. Condom use is determined by several factors: social, economic, cultural and personal. Some factors may be related to general beliefs about condoms. In this regard, it is worth mentioning that the condom has been stigmatized in many counties and in Egypt its use for family planning had not been very successful. Yet limited studies have been geared towards finding reasons for this failure. It is thus important to study whether PLHA, who are the primary sufferers of the consequences of HIV infection, utilize condoms or not and what are the factors affecting condom use. This study was thus an attempt to determine condom use among PLHA in Egypt and related factors.
The results of this study showed that although PLHA knew about condoms and that the great majority of them had been trained on their use, in addition to the fact that condoms are easily available, yet the rate of utilization particularly on a regular basis was lower than expected especially in casual relationships. One of the possible factors behind this low utilization is the fact that the study population was taking antiretroviral therapy. This may be due to the belief that antiretroviral therapy results in decreased HIV viral load and accordingly the probability of transmitting infection decreases. This finding was noted in other studies, in which the prevalence of unprotected sex increased among PLHA receiving HAART [5-8].

It is noted, however, that reported use of condoms was significantly more frequent during sexual relations with regular partners than in casual sexual relations. This study showed that intention to use condoms in the future was nearly the same as that of past and present use, which indicates the need for working with PLHA to change their attitudes towards greater use of condoms.

This study showed that one of the determinants of condom use was the serostatus of the partner, as the tendency to use condoms was greater with a partner with an unknown or a negative serostatus than with a seropositive partner for whom the decision to use condoms was lowest. This may be due to the belief that as long as both partners are positive there is no added risk and so no need to use condoms.

\begin{tabular}{|c|c|c|c|c|c|c|}
\hline \multirow[t]{2}{*}{ Belief } & \multicolumn{2}{|c|}{ Yes } & \multicolumn{2}{|c|}{ No } & \multicolumn{2}{|c|}{ Don't know } \\
\hline & No. & $\%$ & No. & $\%$ & No. & $\%$ \\
\hline \multicolumn{7}{|l|}{ Positive impacts } \\
\hline Prevents transmitting infection to partner & 282 & 83.4 & 14 & 4.1 & 42 & 12.4 \\
\hline Protects you from STI & 278 & 82.2 & 17 & 5.0 & 43 & 12.7 \\
\hline Protects from another HIV infection & 267 & 79.0 & 24 & 7.1 & 47 & 13.9 \\
\hline Prevents guilt feeling afterwards & 223 & 66.0 & 38 & 11.2 & 77 & 22.8 \\
\hline Allows you to continue sexual relationship & 201 & 59.5 & 53 & 15.7 & 84 & 24.9 \\
\hline \multicolumn{7}{|l|}{ Negative impacts } \\
\hline Decreases pleasure & 189 & 55.9 & 59 & 17.5 & 90 & 26.6 \\
\hline Prevents spontaneity & 146 & 43.2 & 75 & 22.2 & 117 & 34.6 \\
\hline Interferes with the flow of sexual relationship & 156 & 46.2 & 80 & 23.7 & 102 & 30.2 \\
\hline Makes a barrier to intimacy and love & 129 & 38.2 & 106 & 31.4 & 103 & 30.5 \\
\hline Causes loss of confidence with partner & 113 & 33.4 & 123 & 36.4 & 102 & 30.2 \\
\hline Results in erection problems & 88 & 26.0 & 135 & 39.9 & 115 & 34.0 \\
\hline
\end{tabular}

$S T I=$ sexually transmitted infections. 


\begin{tabular}{lrc}
\hline $\begin{array}{l}\text { Table } 8 \text { Reasons given by the study population for use and non-use of condoms by } \\
\text { people living with HIV/AIDS, Egypt } 2011\end{array}$ & No. \\
\hline Item & 298 & 93.7 \\
Reasons for use & 14 & 4.4 \\
$\quad$ Protection from infection & 8 & 2.5 \\
Fear of God & 14 & 4.4 \\
Guilt feelings & & $(\boldsymbol{n}=\mathbf{2 8 9})$ \\
Psychological reasons & 159 & 55.5 \\
Reasons for non- $u$ se & 128 & 44.4 \\
Revenge and lack of conscience & 95 & 32.9 \\
To get full pleasure & 59 & 20.5 \\
Ignorance & 21 & 7.3 \\
Psychological factors & 21 & 7.3 \\
Partner refusal & & \\
Unavailability of condom & & \\
\hline
\end{tabular}

As the use of condoms during casual sexual relationships was found to be modest, the study investigated the beliefs of the studied population of PLHA on the impact of condom use in casual sexual relationships. Although more than $80 \%$ of the respondents knew the value of condom use in preventing transmission and protecting against STIs, and two-thirds believed that it saved them from feeling guilty, yet they were not always using condoms in these relations because of factors including decreased pleasure and loss of confidence with the partner. Unavailability of condoms on the spot was not mentioned except by a very small percentage of the respondents.

When asked an indirect question about why PLHA do not use condoms, one reason that emerged, according to more than half the respondents, was revenge, although this was not mentioned when they were speaking about themselves. This suggests that respondents were in denial about their motives or reluctant to admit to such an unethical reason. It means that it should be taken into consideration in programmes designed to change attitudes of PLHA with respect to condom use.
Finally, the responses of participants concerning "fear from God", and other items such as forbidding relations outside marriage, morality and compassion for others, suggest that the strong religious beliefs among the great majority of Egyptians could be used in the counselling of HIV-infected persons. The consultation organized by the World Health Organization Regional Office for the Eastern Mediterranean about the role of religion and ethics in the prevention and control of AIDS has highlighted the need to utilize religious teachings in making affected persons aware of their role in preventing spread of infection to others [18].

\section{Acknowledgements}

We would like to express our special thanks to the United Nations Population Fund (UNFPA) and the National AIDS Control Programme (NAP) for making the achievement of this research possible and for their help and support. Thanks are also due to the people living with HIV/AIDS for their kind cooperation.

Funding: The study was funded by UNFPA and NAP.

Competing interests: None declared.

\section{References}

1. Working Group on Global HIV/AIDS and STI Surveillance. AIDS epidemic update, global overview. Geneva, Joint United Nations Programme on HIV/AIDS/World Health Organization, 2007.

2. Report on the global AIDS epidemic, status of the global HIV epidemic. Geneva, Joint United Nations Programme on HIV/ AIDS/World Health Organization, 2008.

3. Factors affecting accessibility and utilization of condom (a community based study). POLICY project. Addis Ababa, The Futures Group International-Ethiopia, 2000.

4. William KA, Cherly SA. Determinants of condom use to prevent HIV infection among youth in Ghana. Journal of Adolescent Health, 1999, 24:63-72.

5. Cooper DA. HAART's first decade: success brings further challenges. Lancet, 2006, 368:427-428.

6. Stolte IG et al. Increase in sexually transmitted infections among homosexual men in Amsterdam in relation to HAART. Sexually Transmitted Infections, 2001, 77:184-186.
7. Akinyemi JO et al. Condom use among antiretroviral therapy patients in Ibadan, Nigeria. Journal of Infection in Developing Countries, 2010, 4:495-502.

8. Chen SY et al. Continuing increases in sexual risk behavior and sexually transmitted diseases among men who have sex with men. American Journal of Public Health, 2002, 92:1387-1388.

9. Heard I et al. Contraceptive use in HIV-positive women. Journal of Acquired Immune Deficiency Syndromes, 2004, 36:714-720.

10. Wilson TE et al. Changes in sexual behavior among HIV-infected women after initiation of HAART. American Journal of Public Health, 2004, 94:1141-1145.

11. Dave SS et al. Sexual behavior, condom use, and disclosure of HIV status in HIV infected heterosexual individuals attending an inner London HIV clinic. Sexually Transmitted Infections, 2006, 82:117-120.

12. Crepaz N, Hart TA, Marks G. Highly active antiretroviral therapy and sexual risk behavior. A meta-analytic review. Journal of the American Medical Association, 2004, 292:224-236. 
13. Lule GS, Gruer LD. Sexual behavior and use of condom among Ugandan students. AIDS Care, 1991, 3:11-19.

14. Kabbash IA et al. Condom use among males (15-49 years) in Lower Egypt: knowledge, attitudes and patterns of use. Eastern Mediterranean Health Journal, 2007, 13:1405-1416.

15. Peltzer K. Factors affecting condom use among South African University students. East African Medical Journal, 2000, 77:46-52.

16. Schutz $\mathrm{M}$ et al. Determinants of condom use among HIVpositive men who have sex with men. International Journal of STD and AIDS, 2011, 22:391-397.
17. AIDS control program. Cairo, Egypt, Ministry of Health and Population, 2011 [in Arabic].

18. Health education through religion. 6. The role of religion and ethics in the prevention and control of AIDS. Alexandria, World Health Organization, Regional Office for the Eastern Mediterranean, 1992 